\title{
Atopic eczema in early childhood could be protective against Type 1 diabetes
}

\author{
J. Rosenbauer, P. Herzig, G. Giani \\ Department of Biometrics and Epidemiology, German Diabetes Research Institute at Düsseldorf University, Germany
}

\begin{abstract}
Aims/hypothesis. According to the Th1/Th2 paradigm Type 1 diabetes and atopic diseases are assumed to be mutually exclusive on the individual level. We analysed the association between Type 1 diabetes and atopic diseases in a case-control design in order to test the hypothesis that atopic diseases in early childhood could protect against Type 1 diabetes.

Methods. We carried out a nationwide populationbased case-control study enrolling 760 cases newlydiagnosed with Type 1 diabetes under five years of age between July 1992 and December 1995 and 1871 controls randomly selected from the general population and individually matched on sex, age and place of residence. Information on atopic diseases was obtained by a mailed parent-administered questionnaire. Data were analysed by multivariate logistic regression adjusting for potential confounders (family history of diabetes, social status, duration of overall breast feed-
\end{abstract}

ing, number of children in family, maternal age at delivery).

Results. Atopic eczema was less frequent in diabetic $(13.3 \%)$ than in non-diabetic children $(18.0 \%)$ and was significantly associated with a reduced risk of Type 1 diabetes. The adjusted odds ratio was 0.71 (95\% CI 0.53-0.96). Hay fever and asthma were not significantly associated with diabetes risk (OR 0.98 (95\% CI $0.47-2.01$ ) and 1.46 (95\% CI 0.70-3.06), respectively). Conclusion/interpretation. In this large populationbased case-control study in pre-school children an inverse association was observed between atopic eczema and Type 1 diabetes. Thus, in accordance with the Th1/Th2 paradigm development of atopic eczema in early childhood could be protective against childhood Type 1 diabetes. [Diabetologia (2003) 46:784-788]

Keywords Type 1 diabetes, pre-school children, casecontrol study, population-based, atopic eczema, asthma, hay fever, Th1/Th2 paradigm.
Type 1 diabetes is a chronic autoimmune disease resulting in the destruction of the pancreatic beta cells [1]. The development of the autoimmune process is thought to depend on both genetic and environmental factors. An imbalance between Th1 and Th2 subfractions of $\mathrm{T}$ helper cells towards a predominantly Th1 immune reactivity pattern seems to play an important

Received: 31 October 2002 / Revised: 23 January 2003 Published online: 11 June 2003

C Springer-Verlag 2003

Corresponding author: Dr. J. Rosenbauer, Department of Biometrics and Epidemiology, German Diabetes Research Institute at Düsseldorf University, Germany

E-mail: Joachim.Rosenbauer@ddfi.uni-duesseldorf.de role in the pathogenesis of the Type 1 diabetes [2, 3]. In contrast, atopic conditions (asthma, hay fever, eczema) are thought to be immune mediated diseases with a predominantly Th2 type immune response $[2,4]$. The antagonism between Th1 and Th2 immune response suggests that Type 1 diabetes and atopic diseases should be mutually exclusive on the individual level. Thus, Th2 mediated diseases might be protective against the development of Th1 mediated diseases and vice versa [2]. However, only few epidemiological studies investigated the association between Type 1 diabetes and atopic disorders. Some studies reported negative associations providing support for the Th1/Th2 paradigm $[5,6,7,8,9,10,11,12]$, however, others have not $[13,14]$. Even positive associations 
have been indicated between Type 1 diabetes and atopic diseases on both the individual $[15,16]$ and the population level [17]. Thus, epidemiological evidence on the association between Type 1 diabetes and atopic disorders is conflicting. Inconsistent findings could be due to a great variety of factors, however, when assessing potentially weak associations small and even moderate sample sizes might lead to variable results between studies due to sample variation.

Therefore, to assess the association between Type 1 diabetes and atopic diseases a large nationwide population-based case-control study was carried out in Germany confined to pre-school children. Assuming the variety of relevant exposures to increase with lifetime the restriction to this age-group might limit the number of potential confounding factors and facilitates the assessment of those risks, which are associated with very young age, as particularly atopic eczema [18].

\section{Subjects and methods}

Selection of cases and controls, data collection. Between July 1992 and December 1995 children newly-diagnosed with Type 1 diabetes under five years of age were registered by the nationwide active hospital-based surveillance system ESPED using monthly reporting cards and in particular recording information on sex, dates of birth and diagnosis and place of residence [19]. Completeness of ascertainment has been estimated to be $85 \%$.

Non-diabetic control subjects individually matched on sex, age ( \pm 12 months) and place of residence were randomly selected from the general population by local registration offices. For each participating case up to six control subjects were selected.

Data was collected by a mailed parent-administered standardized questionnaire and, if necessary, completed by a telephone interview. Due to legal directions on protection of personal data, hospitals and regional registration offices were not allowed to provide the study group with names and addresses of diabetic patients and selected control children. Therefore, questionnaires together with information on the study had to be sent to reporting paediatricians and regional registration offices requesting them to forward the material to case and control families. Questionnaires were sent out to case families immediately after registration of new diabetic cases so that case families received the questionnaire within a few weeks after children's diabetes onset. Control families received the questionnaire immediately after random selection via regional registration offices. Thus, age range of case and control children was 0 to 5 years and 0 to 6 years, respectively, when the questionnaire was administered.

Information on children's history of atopic diseases was collected by the following simple questions also included in the ISAAC core questionnaires [20]: Has your child ever had asthma (yes/no), hay fever (yes/no), eczema (yes/no) (before diabetes onset)? Questionnaire data further included information on potential confounding factors: family history (parents, siblings or grandparents) of Type 1 diabetes (yes/no), family's socio-economic status (low, middle, high) based on parents' highest level of school education and occupational status, duration of overall breastfeeding (not at all or $<2$ weeks, 2-6 weeks, 7 weeks -4 months, $\geq 5$ months), number of children in the family $(1,2, \geq 3)$, maternal age at delivery $(\leq 20,21-25$, $26-40, \geq 41$ years).

The study was approved by the local ethics committee and the government authorities for the protection of personal information.

Study sample. Questionnaires were sent to 1069 case families (93\% of eligible) and 4385 control families. Altogether, 760 case $(71 \%)$ and $1871(43 \%)$ control families returned a completed questionnaire and were included in the analyses. $26.7 \%$ of matched sets had one control, $29.2 \%$ two controls and $44.1 \%$ three or more controls. $55.4 \%$ of diabetic children and $54.3 \%$ of non-diabetic controls were male. Mean age (SD) of cases and controls was 36.3 (14.2) months and 40.1 (15.0) months, respectively.

Statistical analysis. The proportion of children with a history of atopic diseases was estimated in diabetic and non-diabetic children. Differences were tested using univariate conditional logistic regression. Multivariate conditional logistic regression [21] was done to estimate odds ratios for atopic diseases adjusting for potential confounders. Furthermore, to increase precision unconditional logistic regression was done after dissolving the matching adjusting for age and sex in addition to the other confounders. Likelihood ratio Chi-squared statistics were used to test for significance of associations. A $p$ value of 0.05 was considered statistically significant.

Statistical analyses were carried out with SAS (SAS for Windows, Release 8.0, SAS Institute, Cary, N.C., USA) or STATA (StataCorp. 2001. Stata Statistical Software: Release 7.0 Stata Corporation, College Station, Tex., USA).

\section{Results}

Proportions of children with a history of atopic disorders among diabetic and non-diabetic children and respective unadjusted and adjusted odds ratios are given in Table 1.

Atopic eczema was less frequent in diabetic than in non-diabetic children. The respective univariate odds ratio indicated a significant inverse association between atopic eczema and the risk of diabetes. The association remained significant after adjustment for potential confounders. In contrast, asthma and hay fever showed no association with the risk of diabetes, respective proportions were similar among diabetic and non-diabetic children.

When age (in months) was included in the conditional logistic model in addition to the other confounders in order to adjust for the non-perfect agematching-on average controls were about four months older than cases - odds ratio estimates did not change substantially. Furthermore, results of unconditional logistic regression were very similar (data not shown).

\section{Discussion}

This large individually matched population-based case-control study in pre-school children showed an 
Table 1. Odds ratios for atopic diseases

\begin{tabular}{|c|c|c|c|c|c|c|}
\hline \multirow{2}{*}{$\begin{array}{l}\text { Atopic } \\
\text { disorder }\end{array}$} & \multirow{2}{*}{$\begin{array}{l}\text { Diabetic cases } \\
\text { Proportion of } \\
\text { children with } \\
\text { history of atopic } \\
\text { disorder }\end{array}$} & \multirow{2}{*}{$\begin{array}{l}\text { Non-diabetic controls } \\
\text { Proportion of } \\
\text { children with } \\
\text { history of atopic } \\
\text { disorder }\end{array}$} & \multicolumn{4}{|c|}{ Odds ratio ${ }^{\mathrm{b}}(95 \% \mathrm{CI})$} \\
\hline & & & Unadjusted & $p$ value & Adjusted $^{\mathrm{c}}$ & $p$ value \\
\hline Atopic eczema & $13.3(87 / 653)$ & $18.0(266 / 1479)$ & $0.66(0.50-0.87)$ & 0.002 & $0.71(0.53-0.96)$ & 0.022 \\
\hline Hay fever & $1.9(12 / 632)$ & $2.2(31 / 1399)$ & $0.91(0.46-1.83)$ & 0.799 & $0.98(0.47-2.01)$ & 0.945 \\
\hline
\end{tabular}

a Data are percentages $(\mathrm{n} / \mathrm{N})$

b Estimated by conditional logistic regression

inverse association between atopic eczema and the risk of Type 1 diabetes. This finding indicates that atopic eczema in early childhood could protect against the development of Type 1 diabetes and provides further support for the Th1/Th2 paradigm [2]. In contrast, asthma and hay fever were not associated with the risk of diabetes. However, asthma and hay fever are most common beyond pre-school age [16, 22]. Thus, focusing on pre-school children our study might not be appropriate to provide conclusive evidence on the association of these conditions with the risk of diabetes.

Some further limitations of our study have to be considered. Response rate was lower among non-diabetic control children than among diabetic cases, probably due to the indirect contact of control families via local registration offices. Further, data were collected retrospectively by parent-administered questionnaires and information on atopic diseases was collected by simple questions without further validation through detailed questions on atopic symptoms e.g. according to the ISAAC questionnaires [20]. Therefore, selection bias, recall bias and misclassification could have affected the observed associations. However, proportions of control children with a history of atopic disorders were within the range of previous reports on young German children relating to either parent-reported physician diagnosed atopic disorders [23] or to parent-reported atopic disorders [22] corresponding to our study. In addition, results have been adjusted for socio-economic status, which is known to be associated with both study participation rates and atopic disorders [24, 25]. Differential recall and misclassification between parents of diabetic and non-diabetic children cannot completely be ruled out, but it seems very unlikely to account for the inverse association between eczema and Type 1 diabetes. Further, non-differential recall and misclassification bias would only have weakened the association.

Atopic eczema. The observed negative association between atopic eczema and Type 1 diabetes is consistent with findings of most previous studies and these studies in part diagnosed atopic eczema/dermatitis by c Adjusted for family history of Type 1 diabetes, family's socio-economic status, duration of overall breastfeeding, number of children in the family, maternal age at delivery

more detailed questionnaires $[5,6,9,10,11,12]$. A Danish survey found the cumulative incidence of atopic dermatitis up to age of 15 years to be about one third lower among diabetic than among non-diabetic children [5]. In the EURODIAB ACE study eczema was associated with the risk of Type 1 diabetes in the 10- to 14-year-old age group, but not in younger age groups, in contrast to our finding [9]. A British study found a significant trend of increasing symptoms of atopic eczema from children with Type 1 diabetes through siblings at risk of Type 1 diabetes to unaffected control children, whereas the self-reported prevalence of physician-diagnosed eczema was similar in all groups. A Swedish study also found a lower prevalence of eczema in diabetic than in non-diabetic children, but the difference was not statistically significant due to a rather small sample size [14]. No association between atopic eczema and the risk of diabetes was reported from a Canadian study [13]. A Scottish study even found an increased risk of eczema in patients with a Th1-mediated autoimmune disease including Type 1 diabetes [16].

Asthma. Recent epidemiological studies also reported a negative association between asthma and associated symptoms and the risk of Type 1 diabetes $[7,8,9,10$, 11]. As with symptoms of eczema, the British study found a significant trend of increasing symptoms of asthma from diabetic children through siblings to control children, whereas the self-reported frequency of a doctor's diagnosis of asthma was similar in all groups [7]. Further, in the EURODIAB ACE study no association was observed in the age group under five years [9], in line with our result. Some case-control studies covering older age groups also did not find an association between asthma and Type 1 diabetes [5, 13, 14]. Recently, even positive associations have been indicated on both the individual and the population level $[15,16,17]$.

Hay fever, allergic rhino-conjunctivitis. The EURODIAB ACE multi-centre study reported an inverse association between allergic rhino-conjunctivitis and 
Type 1 diabetes in the 10- to 14-year-old age group [9]. Inconsistent findings were reported from a study in the Netherlands. While symptoms of hay fever separately were less common among diabetic children than among non-diabetic children [11], hay fever defined as presence of symptoms and a doctor's diagnosis was significantly more common among diabetic children [10]. Likewise, allergic rhinitis was more prevalent among diabetic children in Sweden [14]. In Scotland a positive association has been observed between allergic rhinitis and Th1-mediated autoimmune diseases [16]. By contrast, in our study the prevalence of hay fever was similar among diabetic and nondiabetic children, in accordance with other previous reports $[5,13]$.

Taken together, there are conflicting reports on the association between atopic disorders and Type 1 diabetes from epidemiological studies - in particular, regarding the different atopic conditions. Inconsistent findings could be due to a variety of factors, e.g. small sample size, method of data collection, age range of probands. However, differing associations between asthma, hay fever and eczema and the risk of diabetes cannot be precluded because immune mechanisms underlying these atopic conditions, although all are associated with Th2 phenotype, are thought to be different [26].

On the one hand, the epidemiological findings of an inverse association between atopic disorders and Type 1 diabetes-most evident for atopic eczema and asthma-provide further evidence of the Th1/Th2 paradigm. Additionally, there is substantial evidence from clinical and experimental data that Th1/Th2 balance is important to the development of atopic and autoimmune diseases [2, 26, 27, 28, 29, 30]. On the other hand, both Type 1 diabetes and atopic diseases have been rising during the last decades [31, 32, 33, 34 ], according to the 'hygiene hypothesis' possibly due to a decrease of infectious diseases in industrialized countries $[35,36]$. This apparent paradox that Type 1 diabetes and atopic disorders share common epidemiological characteristics but represent opposite deviations of the immune response remains to be resolved [36]. However, the Th1/Th2 paradigm has been discussed to be an oversimplification [2, 27] and in the meantime it has become clear that much more information is needed to understand the regulation of Th1 and Th2 immune responses and their impact on the development of autoimmune and atopic diseases $[2,27]$.

In this large population-based case-control study in pre-school children an inverse association was observed between atopic eczema and Type 1 diabetes. In accordance with the Th1/Th2 paradigm this finding indicates that development of atopic eczema in early childhood and factors predisposing to this condition could be protective against childhood Type 1 diabetes.
Acknowledgements. The study was supported by the German Federal Ministry of Health, the Ministry of Sciences and Research of the Federal State of North Rhine-Westphalia and the Deutsche Forschungsgemeinschaft (He 234/1-1). We thank all the physicians and staff of hospitals supporting our study. In particular, we are grateful to all the families participating in the study.

\section{References}

1. Atkinson MA, Maclaren NK (1994) The pathogenesis of insulin-dependent diabetes mellitus. N Engl J Med 331:1428-1436

2. Prahalad S (2000) Atopy, autoimmunity, and the TH1/TH2 balance. J Pediatr 137:446-449

3. Katz JD, Benoist C, Mathis D (1995) T helper cell subsets in insulin-dependent diabetes. Science 268:11851188

4. Del Prete G (1992) Human Th1 and Th2 lymphocytes: their role in the pathophysiology of atopy. Allergy 47:450-455

5. Olesen AB, Juul S, Birkebaek N, Thestrup-Pedersen K (2001) Association between atopic dermatitis and insulindependent diabetes mellitus: a case-control study. Lancet 357:1749-1752

6. Douek IF, Leech NJ, Bingley PJ, Gale EA (2002) Eczema and Type 1 diabetes. Diabet Med 19:174-175

7. Douek IF, Leech NJ, Gillmor HA, Bingley PJ, Gale EA (1999) Children with type-1 diabetes and their unaffected siblings have fewer symptoms of asthma. Lancet 353: 1850

8. Mattila PS, Tarkkanen J, Saxen H, Pitkaniemi J, Karvonen M, Tuomilehto J (2002) Predisposition to atopic symptoms to inhaled antigens may protect from childhood type 1 diabetes. Diabetes Care 25:865-868

9. The EURODIAB Substudy 2 Study Group (2000) Decreased prevalence of atopic diseases in children with diabetes. J Pediatr 137:470-474

10. Meerwald R, Odink RJ, Landaeta R, et al. (1998) Prevalence of atopy in children with diabetes mellitus type 1 . Horm Res 50:125 (Abstract)

11. Meerwald R, Odink RJ, Landaeta R, et al. (2002) A lower prevalence of atopy symptoms in children with type 1 diabetes mellitus. Clin Exp All 32:254-255

12. Hermansson B, Holmgren G, Samuelson G (1971) Juvenile diabetes mellitus and atopy. Hum Hered 21:504508

13. Siemiatycki J, Colle E, Campbell S, Dewar RA, Belmonte MM (1989) Case-control study of IDDM. Diabetes Care 12:209-216

14. Strömberg LG, Ludvigsson GJ, Bjorksten B (1995) Atopic allergy and delayed hypersensitivity in children with diabetes. J Allergy Clin Immunol 96:188-192

15. Kero J, Gissler M, Hemminki E, Isolauri E (2001) Could TH1 and TH2 diseases coexist? Evaluation of asthma incidence in children with coeliac disease, type 1 diabetes, or rheumatoid arthritis: a register study. J Allergy Clin Immunol 108:781-783

16. Simpson CR, Anderson WJ, Helms PJ, et al. (2002) Coincidence of immune-mediated diseases driven by Th1 and Th2 subsets suggests a common aetiology. A populationbased study using computerized general practice data. Clin Exp Allergy 32:37-42

17. Stene LC, Nafstad P (2001) Relation between occurrence of type 1 diabetes and asthma. Lancet 357:607-608 
18. Williams HC, Strachan DP (1998) The natural history of childhood eczema: observations from the British 1958 birth cohort study. Br J Dermatol 139:834-839

19. Rosenbauer J, Herzig P, Kries R von, Neu A, Giani G (1999) Temporal, seasonal, and geographical incidence patterns of Type I diabetes mellitus in children under 5 years of age in Germany. Diabetologia 42:1055-1059

20. Asher MI, Keil U, Anderson HR, et al. (1995) International Study of Asthma and Allergies in Childhood (ISAAC): rationale and methods. Eur Respir J 8:483-491

21. Breslow NE, Day NE (1980) Statistical methods in cancer research, vol 1-The analysis of case-control studies. International Agency for Research on Cancer, Lyon (IARC Scientific Publications No. 32)

22. Duhme H, Weiland SK, Rudolph P, Wienke A, Krämer A, Keil U (1998) Asthma and allergies among children in West and East Germany: a comparison between Münster and Greifswald using the ISAAC phase I protocol. International Study of Asthma and Allergies in Childhood. Eur Respir J 11:840-847

23. Trepka MJ, Heinrich J, Wichmann HE (1996) The epidemiology of atopic diseases in Germany: an east-west comparison. Rev Environ Health 11:119-131

24. Williams HC, Strachan DP, Hay RJ (1994) Childhood eczema: disease of the advantaged? BMJ 308:1132-1135

25. Heinrich J, Popescu MA, Wjst M, Goldstein IF, Wichmann HE (1998) Atopy in children and parental social class. Am J Public Health 88:1319-1324

26. Biedermann T, Röcken M (1999) Th1/Th2 balance in atopy. Springer Semin Immunpathol 21:295-316
27. Wedderburn L, Woo P (1999) Type 1 and type 2 immune responses in children: their relevance in juvenile arthritis. Springer Semin Immunopathol 21:361-374

28. Shirakawa T, Enomoto T, Shimazu S, Hopkin JM (1997) The inverse association between tuberculin responses and atopic disorder. Science 275:77-79

29. Liblau RS, Singer SM, McDevitt HO (1995) Th1 and Th2 CD4+ T cells in the pathogenesis of organ-specific autoimmune diseases. Immunol Today 16:34-38

30. Sarvetnick N, Shizuru J, Liggitt D, et al. (1990) Loss of pancreatic islet tolerance induced by beta-cell expression of interferon-gamma. Nature 346:844-847

31. Green A, Patterson CC (2001) Trends in the incidence of childhood-onset diabetes in Europe 1989-1998. Diabetologia 44 Suppl 3:B3-B8

32. Onkamo P, Vaananen S, Karvonen M, Tuomilehto J (1999) Worldwide increase in incidence of Type I diabetes-the analysis of the data on published incidence trends. Diabetologia 42:1395-1403

33. Kuehni CE, Davis A, Brooke AM, Silverman M (2001) Are all wheezing disorders in very young (preschool) children increasing in prevalence? Lancet 357:1821-1825

34. Mutius E von, Weiland SK, Fritzsch C, Duhme H, Keil U (1998) Increasing prevalence of hay fever and atopy among children in Leipzig, East Germany. Lancet 351:862-866

35. Bach JF (2002) The effect of infections on susceptibility to autoimmune and allergic diseases. $N$ Engl J Med 347:911-920

36. Gale EAM (2002) A missing link in the hygiene hypothesis? Diabetologia 45:588-594 